\title{
Microanatomy of the Rat Diaphragm: A Scanning Electron and Confocal Laser Scanning Microscopic Study
}

\author{
Yuko Ohtani ${ }^{1}$, Osamu OHTANi ${ }^{2}$ and Toshio NaKatani ${ }^{2}$ \\ Second Department of Internal Medicine ${ }^{1}$, Okayama University School of Medicine, Okayama; and Department of Anatomy ${ }^{2}$, \\ Toyama Medical and Pharmaceutical University, Toyama, Japan
}

Received June 8, 1993

\begin{abstract}
Summary. The present study demonstrated the threedimensional microstructure of the rat diaphragm by scanning electron microscopy (SEM) of either intact or alkali-treated tissues, enzyme-histochemistry, and confocal laser scanning microscopy (LSM). The peritoneal and pleural surfaces of the diaphragm were covered with mesothelial cells studded with microvilli. Many round gaps were formed between the mesothelial cells. The submesothelial connective tissue contained voluminous, irregularly shaped lymphatics. Some of these lymphatics extended many funnel-like projections of their endothelia towards the pored region of the mesothelium. On coming into contact with the mesothelium, many of the lymphatic projections were perforated at their ends, thus giving rise to stomata connecting the peritoneal cavity and lymphatic lumen. Some projections ended blindly while plugging the mesothelial pores, thereby making visible some intercellular gaps in this contact. The subperitoneal sheet of the collagen fiber network possessed clusters of foramina which tightly fit the passage of the lymphatic projections. Confocal LSM of the diaphragm after intraperitoneal injection of FITC-dextran demonstrated the tracer both in the lymphatic lumina and in the connective tissue spaces. Our results indicate that peritoneal fluid is allowed to flow into the connective tissue spaces of the diaphragm through intercellular gaps and into lymphatics through stomata.
\end{abstract}

Since EDWARDS and UNGAR (1967) first reported the hydrothorax as a complication of peritoneal dialysis, the incidence of a hydrothorax related to continuous ambulatory dialysis (CAPD) and intermittent peritoneal dialysis (IPD) has been documented to be $2-10 \%$ of all cases of peritoneal dialysis (LORENTZ, 1979; RUDNICK et al., 1979; PARAMSOTHY et al., 1985; BOESCHOTEN et al., 1986; BJERKE et al., 1991). Although the mechanism by which the hydrothorax occurs during CAPD and IPD remains sketchy, there must be some structural bases which permit the peritoneal fluid to pass across the diaphragm to enter the pleural cavity.

One hundred and thirty years have passed since RECKLINGHAUSEN (1863) first described the lymphatic stomata of the diaphragm. However, that the stomata actually function for fluid drainage from the peritoneal cavity has only lately been established (LEAK and RAHIL, 1978; BETTENDORF, 1978, 1979; TSILIBARY and WISSIG, 1983, 1987). A more recent study has precisely depicted the stomata and underlying foramina in the collagen fiber network by transmission (TEM) and scanning electron microscopy (SEM) (OYA et al., 1993). Nevertheless, we still do not fully understand the spatial relationships of the lymphatic vessels to the mesothelial stomata and to the connective tissue spaces.

In order to reveal the possible passageway of peritoneal fluid to the thoracic cavity, we examined the three-dimensional organizaton of the diaphragm using a variety of methods. These included SEM of $\mathrm{KOH}$ treated tissues for demonstrating the organization of cellular elements (MILLER et al., 1982; USHIKI and IDE, 1988), SEM of NaOH-macerated tissues for showing the collagen fiber network (OHTANI, 1987; OHTANI et al., 1988) and light microscopy in conjunction with enzyme ( $5^{\prime}$-nucleotidase)- histochemistry for identification of lymphatics (WERNER et al., 1987; KATO and MiYAUCHI, 1989). Confocal laser scanning microscopy (LSM) of the diaphragm after intraperitoneal injection of FITC-dextran was also conducted to reveal the actual passageway of peritoneal fluid.

\section{MATERIALS AND METHODS}

Eight adult rats were used: two for SEM of cellular elements, one for SEM of collagen fiber network, two 
for enzyme-histochemistry and three for confocal LSM.

\section{SEM of cellular elements}

Under deep anesthesia with diethyl ether, the thorax was opened and a catheter was introduced into the ascending aorta through an incision in the left ventricle. The rat was perfused with saline through the catheter, which was followed by perfusion fixation with $2 \%$ glutaraldehyde in $0.1 \mathrm{M}$ phosphate buffer (pH 7.4). The diaphragm was excised, and cut into several pieces which were immersed in the same fixative for a day. The specimens were then placed in $5 \mathrm{~N} \mathrm{KOH}$ for $10 \mathrm{~min}$ at $60^{\circ} \mathrm{C}$. After immersing in phosphate buffer for $30 \mathrm{~min}$, they were fixed in $1 \%$ tannic acid for $3 \mathrm{~h}$, extensively rinsed and then fixed in $1 \% \mathrm{OsO}_{4}$ for $3 \mathrm{~h}$. The specimens were dehydrated through ethanol, critical point-dried, mounted on metal stubs, coated with gold and observed under a Topcon Supper III SEM at an accelerating voltage of $15 \mathrm{kV}$.

\section{SEM of collagen fiber network}

The pieces of the diaphragm fixed in the same way as above were placed in $2 \mathrm{~N} \mathrm{NaOH}$ for 5 days at $25^{\circ} \mathrm{C}$. They were then placed in distilled water for 3 days at room temperature. With these procedures, all of the cells were macerated away and only collagen fibers remained. The samples were fixed in 1\% tannic acid for $2 \mathrm{~h}$. After rinsing in distilled water, they were fixed in $1 \% \mathrm{OsO}_{4}$ for $2 \mathrm{~h}$, dehydrated through ethanol, critical point-dried, mounted on metal stubs, coated with gold and observed under the SEM at an accelerating voltage of $15 \mathrm{kV}$.

\section{Enzyme-histochemistry}

Under deep anesthesia with diethyl ether, the rat was perfused with saline through the catheter inserted into the ascending aorta, which was followed by perfusion fixation with $4 \%$ paraformaldehyde in 0.1 M cacodylate buffer. The diaphragm was excised, and placed in the same fixative overnight. After

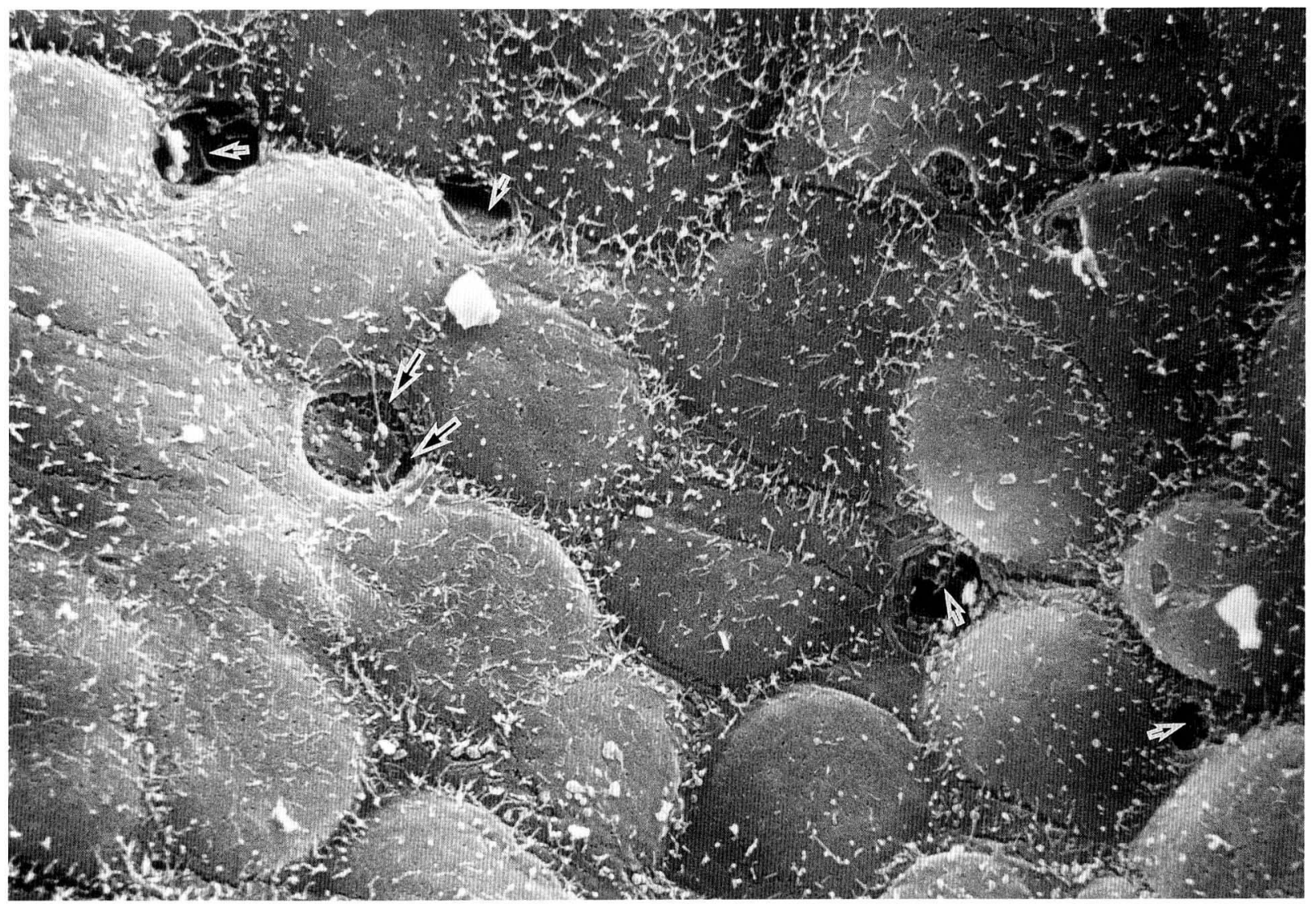

Fig. 1. SEM of the rat peritoneal mesothelium studded with microvilli. Between the mesothelial cells are round stomata through which prolongations of the lymphatic endothelial cells (small arrows) are seen. The endothelial cells are mostly in contact with the mesothelial cells, but there are also some gaps between them (larger arrows). $\times 3,550$ 
immersing for $30 \mathrm{~min}$ in the $0.1 \mathrm{M}$ cacodylate buffer containing $1 \%$ triton-X 100 , the diaphragm was incubated for $40 \mathrm{~min}$ in a lead-based standard medium for $5^{\prime}$-nucleotidase reaction according to the method by WACHSTEIN and MEISEL (1957). The standard medium consisted of $20 \mathrm{ml} 0.2 \mathrm{M}$ Tris-maleate buffer (pH 7.2), $25 \mathrm{mg}$ 5'-adenosine monophosphate (AMP sodium salt, Sigma), $123 \mathrm{mg} \mathrm{MgSO}_{4}, 3 \mathrm{~g}$ sucrose, 60 $\mathrm{mg} \mathrm{Pb}\left(\mathrm{NO}_{3}\right)$ and $30 \mathrm{ml}$ distilled water. The medium was augmented with $20 \mathrm{mg}$ L-tetramisole to obtain specific reaction for 5 '-nucleotidase activity (WERNER et al., 1987). The diaphragm was rinsed in distilled water, immersed in $1 \%$ yellow ammonium sulfate solution for 2 min and examined under a light microscope.

\section{Confocal laser scanning microscopy}

The rats were injected intraperitoneally with $1 \%$ FITCdextran (average MW 147,800) resolved in saline. Twenty to $30 \mathrm{~min}$ after the injection, the diaphragm was excised under deep anesthesia with diethyl ether, and observed under an Olympus LSM-GB200 confocal LSM.

\section{RESULTS}

\section{SEM of the mesothelial surface}

Both pleural and peritoneal surfaces of the diaphragm appeared covered with mesothelial cells studded with numerous microvilli (Fig. 1). The nuclear portion of the mesothelial cell slightly bulged towards the body cavities. The mesothelial cells of the peritoneum extended, in some regions, long processes which interdigitated with processes of neighboring cells. In such areas there were clusters of many intercellular stomata which were round or oval in shape and measured less than $15 \mu \mathrm{m}$ in diameter (Fig. 1). The pleural mesothelium did not possess stomata. Flat prolongations of lymphatic endothelial cells (see below) contacted the rims of the mesothelial stomata, and thus the peritoneal cavity were continuous with the lymphatic lumen through the stomata. However, a round disclike endothelial projection was occasionally seen plugging the mesothelial stoma. There were recognizable gaps between such an endothelial projection and the margin of the mesothelial stoma (Fig. 1).

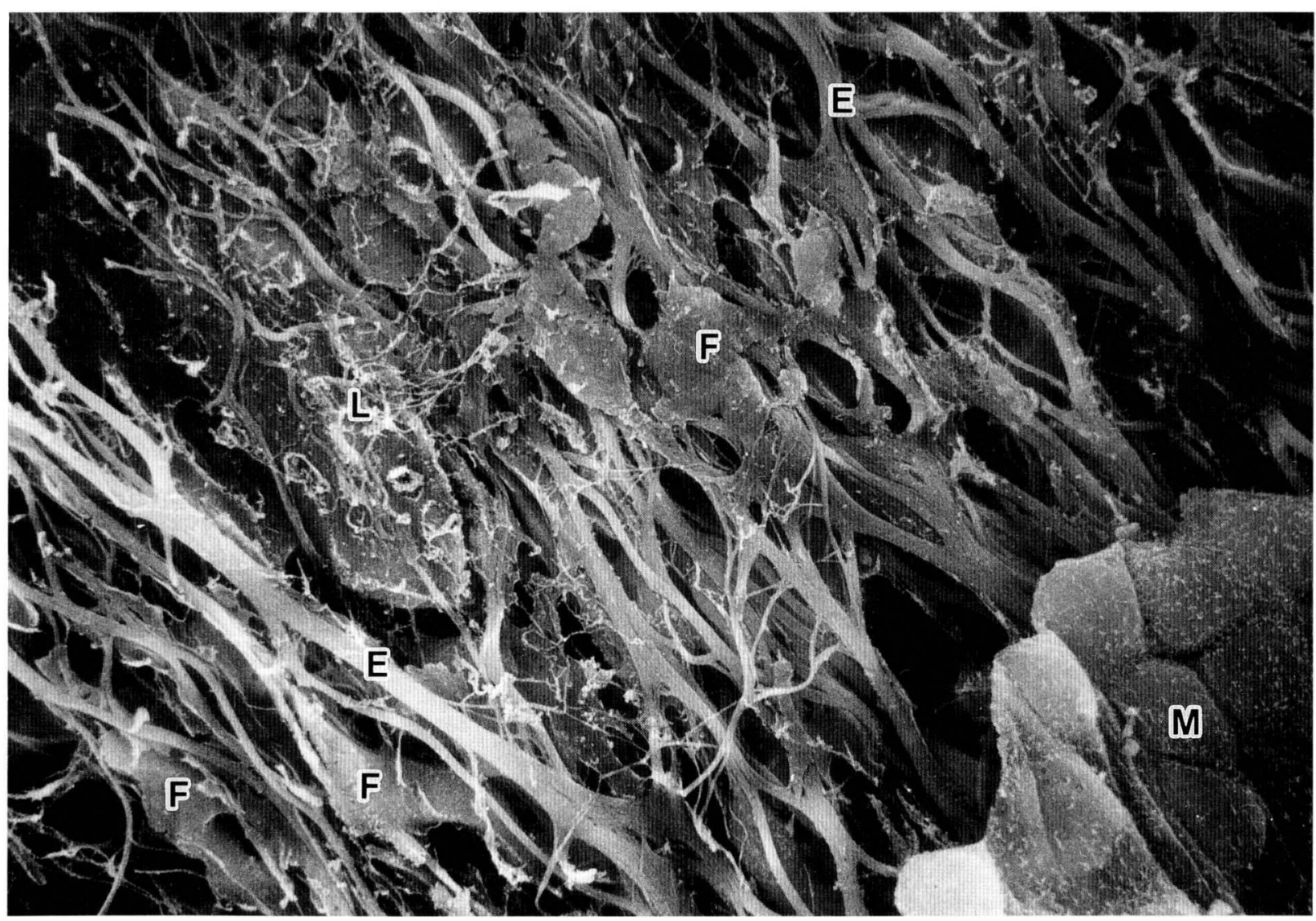

Fig. 2. SEM of $\mathrm{KOH}$-treated rat diaphragm. Below the peritoneal mesothelium $(M)$ are elastin fiber network $(E)$ within which fibroblasts $(F)$ are scattered. An initial lymphatic $(L)$ is seen emerging through the elastin fiber network. $\times 1,750$ 


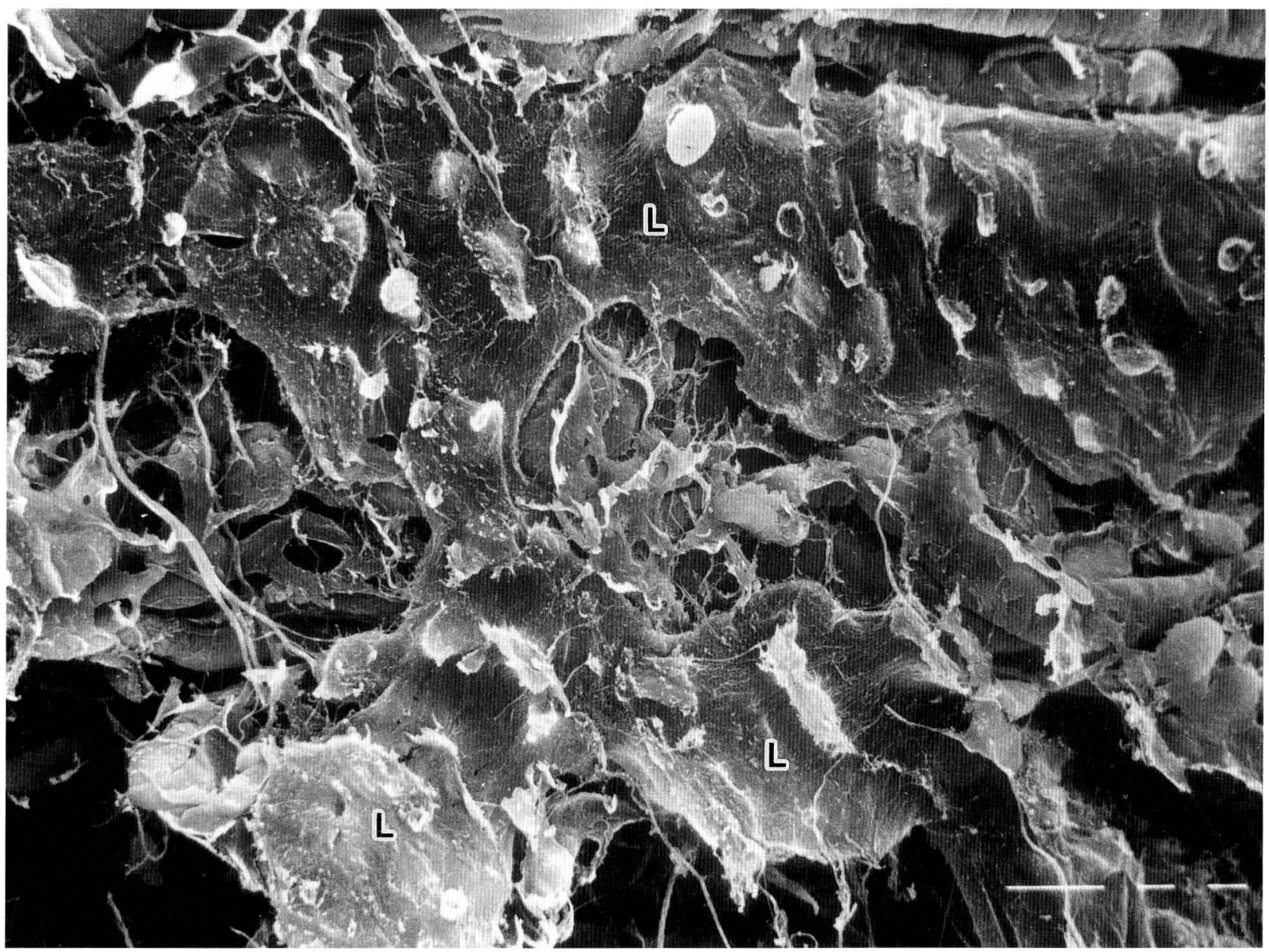

Fig. 3. SEM of KOH-treated rat diaphragm showing a lymphatic vessel $(L)$ below the mesothelium. The lymphatic vessel is irregular in shape and protrudes many funnel-like projections. $\times 1,250$

\section{SEM of KOH-treated diaphragm}

The $5 \mathrm{~N} \mathrm{KOH}$-treatment at $60^{\circ} \mathrm{C}$ for $10 \mathrm{~min}$ removed all of the collagen fibers, and thus allowed layer by layer examination of the diaphragm by simple dissection such as blowing away or taking off superficial structures. In the submesothelial space, there appeared an elastin fiber network in which fibroblasts were dispersed. Blind-ended lymphatics frequently emerged between the elastin fibers (Fig. 2). When the elastin fiber network was successfully removed by microdissection with fine tweezers or blown away, the lymphatics were exposed in wider ranges. On the mesothelial side of the subperitoneal lymphatics with flat irregular shapes were many funnel-like projections of the endothelium (Fig. 3). These projections were apparently larger in number than the mesothelial stomata. Most of the projections formed a round pore or pores leading into the lymphatic lumen (Fig. 4a, b), though some did not possess such pores but showed only narrow gaps between the endothelial flaps. Moreover, there were endothelial projections which were completely closed (Fig. 4c, d). This type of closed endothelial projection was especially numerous around the very initial part of the lymphatics (Fig. 4d).

\section{SEM of collagen fiber network}

The $2 \mathrm{~N} \mathrm{NaOH}$-maceration at room temperature followed by rinsing in distilled water removed cellular elements, thus exposing the three-dimensional organization of collagen fibers under SEM. Immediately below the mesothelium was a sheet-like network made up of interwoven collagen fibrils. Below the network there were thicker collagen fibers which took zigzagging or spiraling courses (Fig. 5).

There were clusters of oval foramina varying from 1 to $8 \mu \mathrm{m}$ in diameter. There were also small foramina which were spanned by several collagen fibrils (Fig. 6). SEM of cross sections of the macerated dia- 

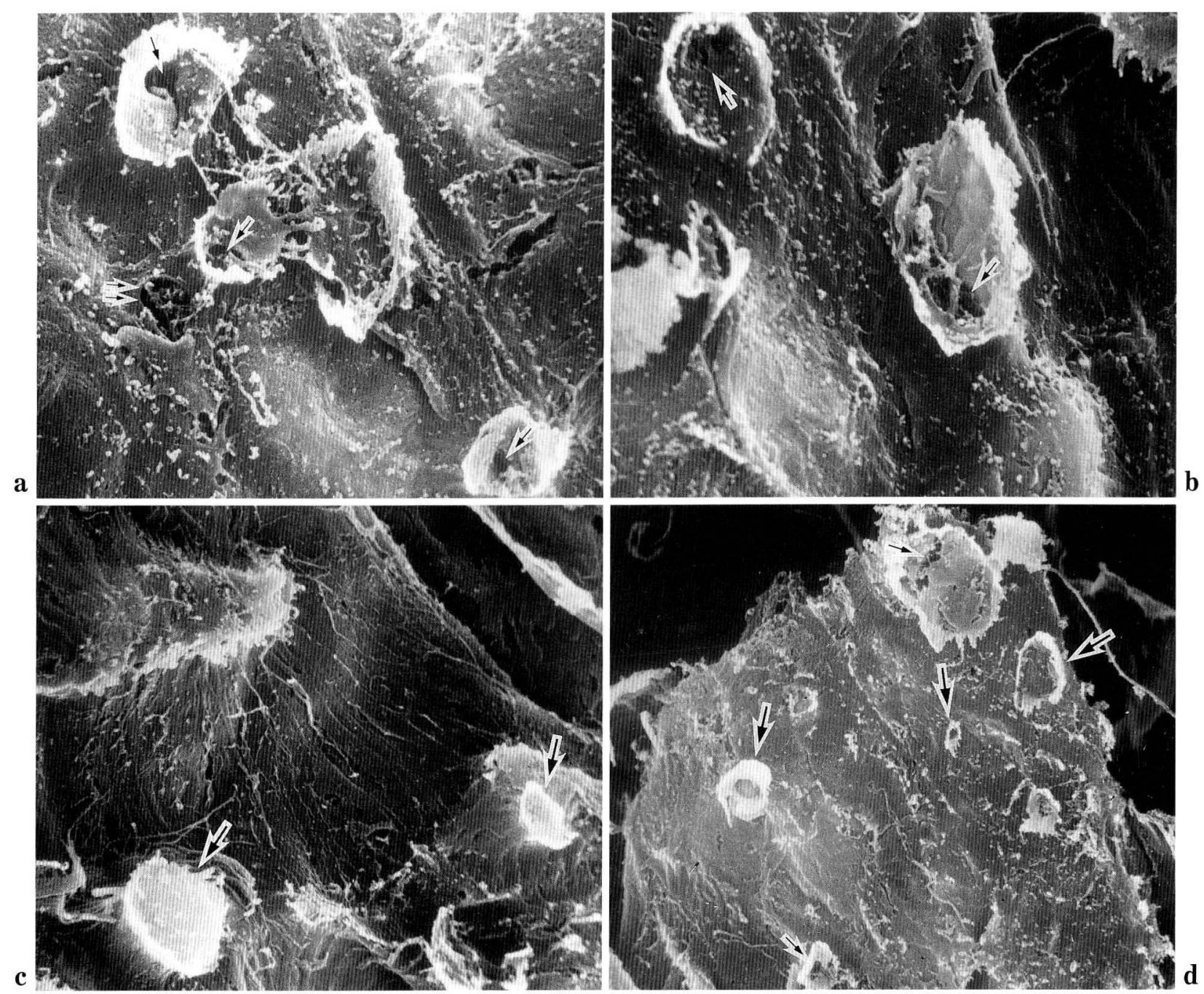

Fig. 4. Closer views of the lymphatics below the peritoneal mesothelium showing various forms of funnel-like projections of the lymphatic endothelial cells. The projections form stomata (small arrows) leading into the lymphatic lumen $(\mathbf{a}, \mathbf{b})$, but there are also projections without stomata (larger arrows)(c, d). A simple gap between lymphatic endothelial cells is also seen (double arrows in a). a, b: $\times 5,500, \mathrm{c}: \times 3,000, \mathrm{~d}: \times 2,800$

phragm showed collagen fiber sheaths for accommodating lymphatics below the submesothelial collagen fiber network (Fig. 7b).

On the peritoneal side of the sheath, there were many foramina through which the peritoneal cavity communicated with the lymphatic lumen (Fig. 7b). Deeper to the submesothelial connective tissue layer were honeycomb-like collagen fiber networks for accommodating muscle fibers. The sheaths consisted of fine interwoven collagen fibers. Between the sheaths there were sparsely distributed thicker collagen fibers and fine collagen fiber sheaths for blood and lymphatic vessels, respectively (Fig. 7). Collagen fiber sheaths for nerves were also occasionally observed.

\section{Enzyme-histochemistry}

The enzyme-histochemistry of the whole mount preparations demonstrated submesothelial lymphatics tinged dark brown as the result of the $5^{\prime}$-nucleotidase reaction (Fig. 8). The diameter of the lymphatics varied from 5 to $100 \mu \mathrm{m}$, but most were within the range of $20-50 \mu \mathrm{m}$. Most of the lymphatics were tubulosacclar in profile, though some showed flat and irregular profiles (Fig. 8a, b). The former type of lymphatics existed in both subperitoneal and subpleural spaces, but the latter were observed predominantly in the subperitoneal space (Fig. 8). Also, the former possessed many valves, while the latter were equipped with few 


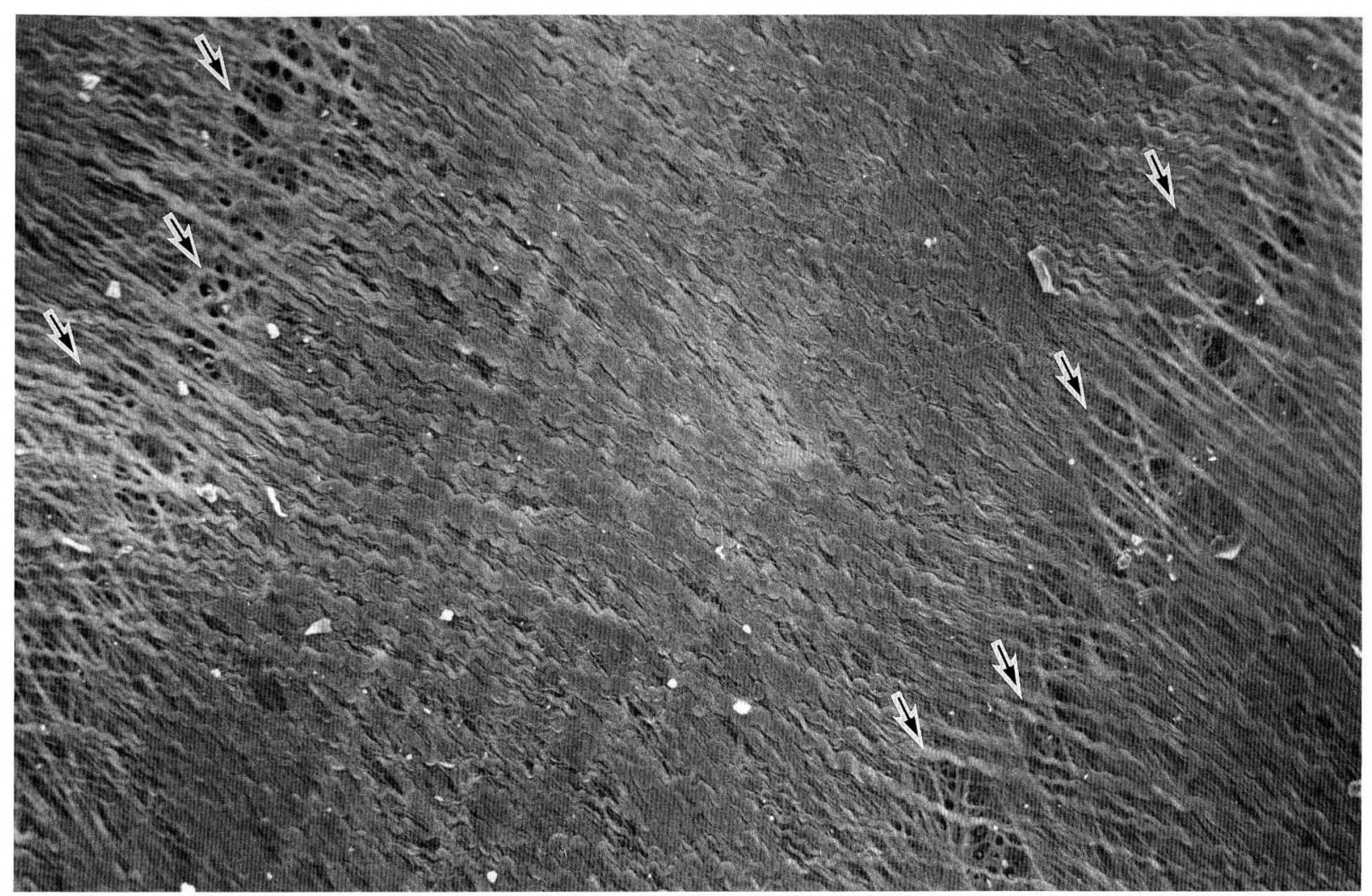

Fig. 5. SEM of the NaOH-macerated rat diaphragm showing the collagen fiber sheet immediately below the mesothelium. There are many clusters of foramina lined in rows (arrows). $\times 170$

of these. Some lymphatics running between the muscle fibers were surrounded by smooth muscle cells which were also tinged dark brown as the result of the $5^{\prime}$-nucleotidase reaction (data not shown).

\section{Confocal laser scanning microscopy}

Confocal LSM of the diaphragm 20-30 min after the intraperitoneal injection of FITC-dextran showed the fluorescent tracer in the lymphatics (Fig. 9). Many free cells were observed as negative images in the lymphatics (Fig. 9b). The tracer was also recognized in the connective tissue space between muscular fibers (Fig. 9c). The confocal LSM also showed the three-dimensional organization of the dense lymphatic network below the peritoneal mesothelium (Fig. 9b).

\section{DISCUSSION}

The present study has clearly shown the three-dimensional organization of the rat diaphragm with a variety of methods including SEM in conjunction with alkali- maceration techniques (Miller et al., 1982; OHTANI, 1987; OHTANI et al., 1988, UsHIKI and IDE, 1988), confocal LSM and enzyme-histochemistry (WERNER et al., 1987; KATO and MrYAUCHI, 1989). It is especially noteworthy that the microdissection of the $\mathrm{KOH}$ treated samples followed by SEM allowed a threedimensional visualization of the subperitoneal initial lymphatics which possessed variously shaped projections with or without stomata. This method would be applicable to study the three-dimensional architecture of lymphatics in other tissues as in our previous study on the rat cecal lymphatic vessels (OHTANI, 1992).

It has long been known that fluids and particulate matters in the peritoneal cavity drain into the lymphatics of the diaphragm and then into the thoracic duct (FRENCH et al., 1960; YAMAGISHI, 1961; KoTANI et al., 1962). Later studies have revealed that erythrocytes and other cells as well as macromolecules in the peritoneal cavity enter the diaphragmatic lymphatics through the mesothelial stomata continuous with lymphatic lacunae (BETTENDORF, 1978, 1979; LEAK and RAHIL, 1978; TSILIBARY and WISSIG, 1983, 1987; FukUO et al., 1990; OYA et al., 1993). In accordance 


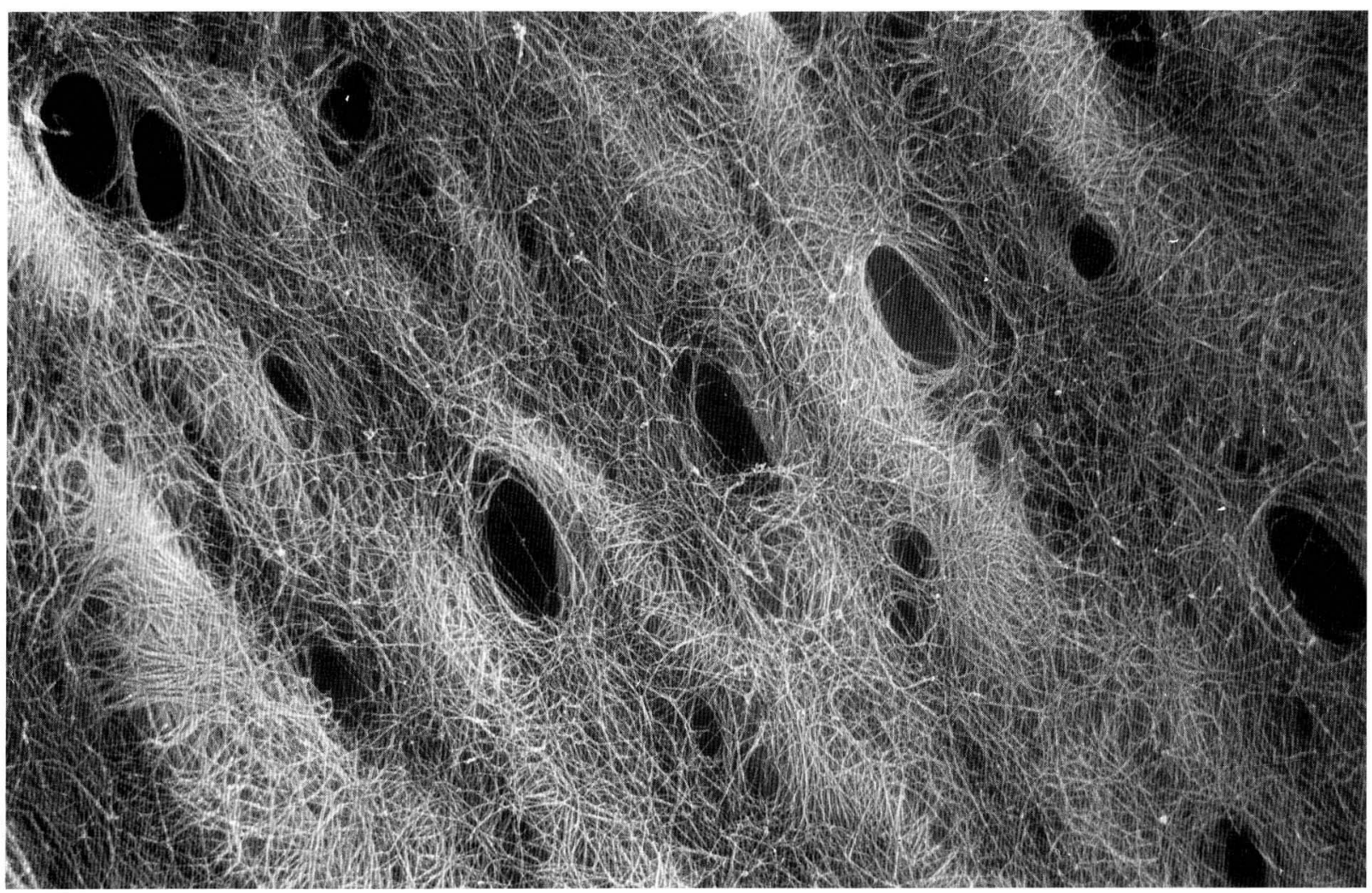

FIg. 6. A closer view of Figure 5. The collagen fiber sheet below the mesothelium possesses round foramina of various sizes. $\times 3,300$

with these previous studies, the present study has further revealed that the peritoneal fluids enter the interstitial tissue spaces of the diaphragm as well as the lymphatics through the mesothelial and lymphatic stomata.

The peritoneal fluids may pass through the mesothelium intracellularly. Indeed, some authors (DiGENIS et al., 1984) have reported that iron dextran injected intravenously was transported intracellularly through the mesothelium into the peritoneal cavity during peritoneal dialysis in the rabbit. In their electron microscopic study, KoTANI et al. (1962) showed that carbon particles passed the mesothelial and endothelial cells intracellularly as well as through intercellular gaps. BETTENDORF (1979) also demonstrated that latex particles (1.1 $\mu \mathrm{m}$ in diameter) were phagocytized by both mesothelial and endothelial cells. However, intracellular transport would not be so efficient as intercellular transport. The present study indicated the occurrence of gaps connecting the mesothelial stomata to the interstitial tissue spaces and to the lymphatic lacunae. This kind of intercellular gap could provide the peritoneal fluids with passageways into the interstitium and into the lymphatic lumina of the diaphragm. Ultrastructural studies on the permeability of rat mesothelium to horseradish peroxidase have also suggested that mesothelial transport can be accounted for by passive diffusion through intercellular clefts (COTRAN and KARNOVSKY, 1968).

That the peritoneal fluids can enter the diaphragm through intercellular gaps seems important when considering the mechanism of the hydrothorax associated with CAPD or IPD. In their TEM and SEM study, DI PAOLO et al. (1986) have demonstrated that, during CAPD, the mesothelial cells reduce their microvilli and widen their intercellular spaces. Moreover, they have shown that during peritonitis associated with CAPD, the mesothelium fall away, leaving behind the bare basement membrane. Similar findings have been reported in animal experiments (RAFFERTY, 1973; VERGER et al., 1983). The pathogenesis of the hydrothorax associated with CAPD is still unclear at this time. Alterations in the mesothelium associated with peritonitis during CAPD would greatly facilitate the entrance of peritoneal fluids into the diaphragm. The intercellular gaps between the pleural mesothelium (FUKUO et al., 1990) would then serve as fluid passageways from the diaphragm to the 

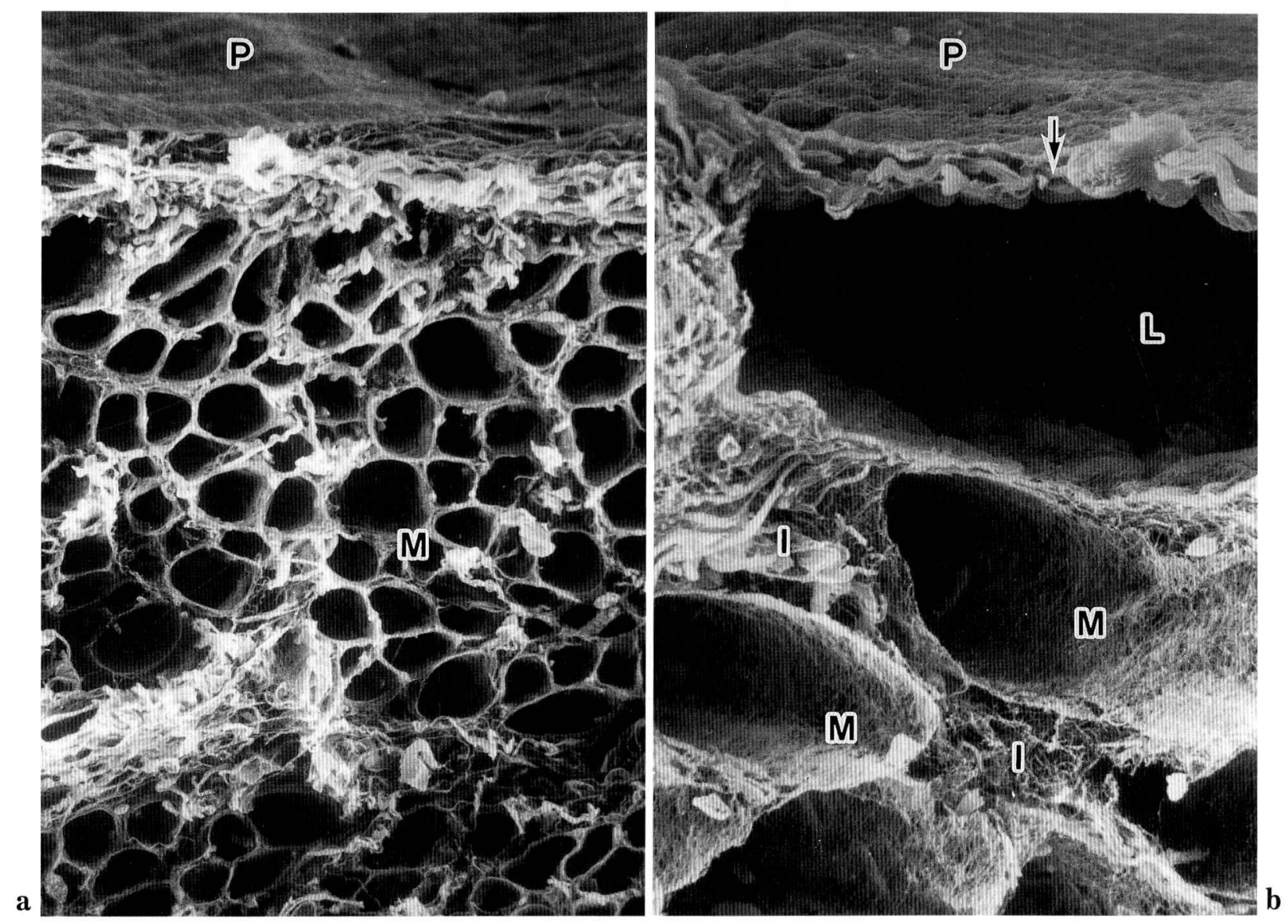

Fig. $7 \mathbf{a}$ and b. SEM of the $\mathrm{NaOH}$-macerated rat diaphragm showing the collagen fiber network below the peritoneal mesothelium $(P)$ and around the muscle fibers $(M)$. An arrow in $\mathbf{b}$ indicates the foramen of the submesothelial collagen fiber sheet continuous with the collagen fiber sheath for a lymphatic vessel $(L)$. The muscle fibers are surrounded by fine interwoven collagen fiber sheaths between which are thick but sparse collagen fibers in the interstitial tissue spaces $(I)$ a: $\times 230, \mathrm{~b}: \times 1,000$

pleural cavity, thus resulting in hydrothorax. There are, however, many other potential factors which include lymphatic obstruction, gross diaphragmatic defects (FINN and JowETT, 1970), ruptured diaphragmatic bullae (BOESCHOTEN et al., 1986) or attenuated diaphragmatic muscle (LORENTZ, 1979; BOESCHOTEN et al., 1986; BJERKE et al., 1991). Further studies will be needed to elucidate the mechanism by which the hydrothorax is associated with CAPD.

The present enzyme-histochemical study has shown the distribution and structure of the submesothelial lymphatics at the light microscopic level. The organization of the subpleural lymphatics herein presented coincides with that in the monkey reported by MASADA et al. (1992). Tubular lymphatics in the subperitoneal and subpleural tissue spaces possess many valves which permit lymph to flow in one directions as observed by ALLEN (1956). It is interest- ing, however, that the flat sacclar lymphatics frequently seen in the subperitoneal tissue spaces possess few valves. These kinds of lymphatic lacunae apparently correspond to those with many funnel-like projections observed under SEM. Since the lymphatics are linked with surrounding interstitial tissues by anchoring filaments (LEAK and BURKE, 1968), the lymphatic lacunae serve as a great potential reservoir which can suck in peritoneal fluids during expiration and push lymph towards conduit lymphatic vessels during inspiration (BETTENDORF, 1978).

Particularly noteworthy is the finding that the submesothelial lymphatic lacunae possess numerous funnel-like projections. Most of the projections have foramina continuous with the lymphatic lumen, thus forming stomata through which peritoneal fluids and particulate matters enter the lymphatics. Some projections, however, apparently did not show any 


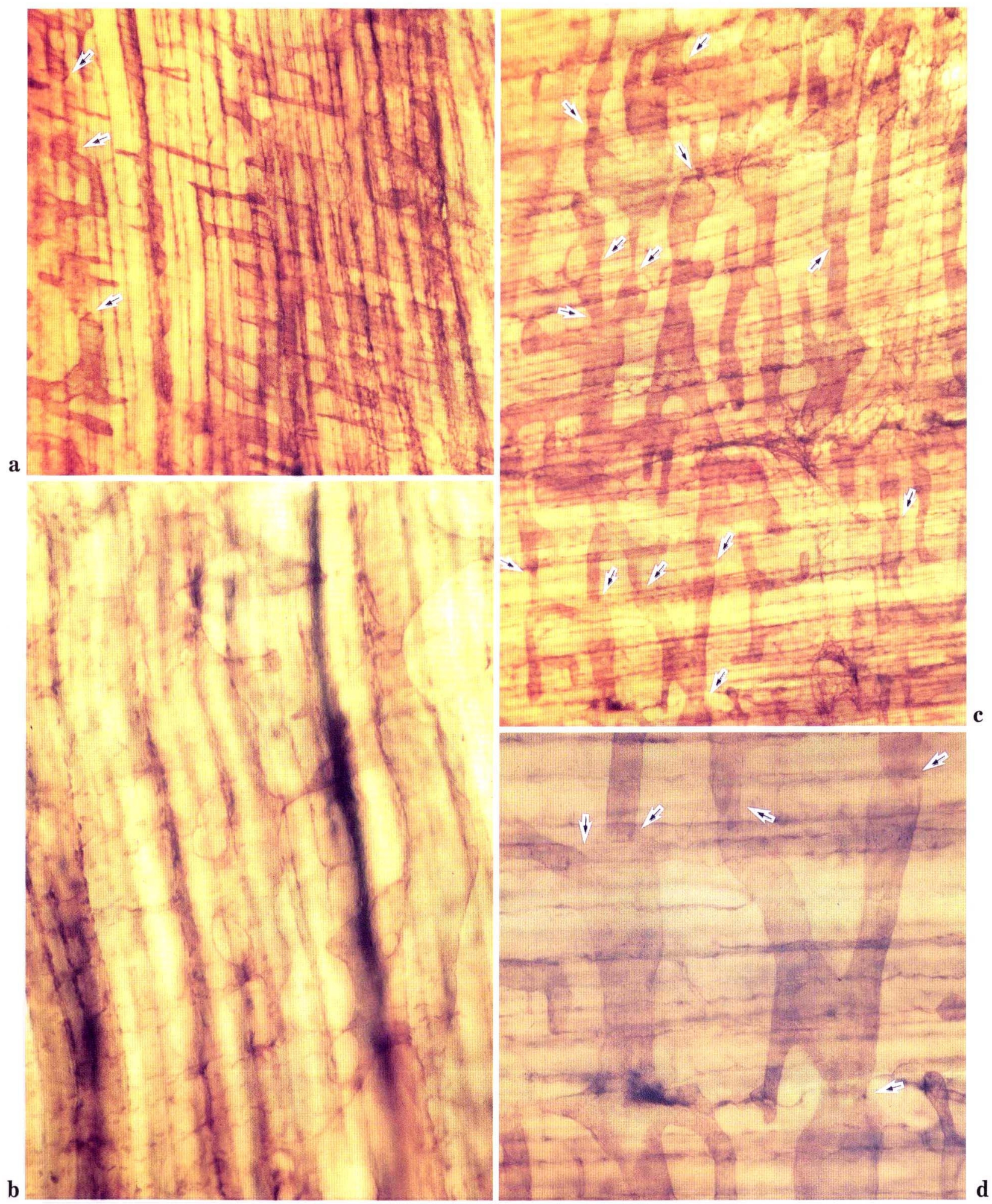

Fig. 8. Enzyme-histochemically stained whole mount diaphragm showing lymphatics (dark brown) in the subperitoneal $(\mathbf{a}, \mathbf{b})$ and subpleural $(\mathbf{c}, \mathbf{d})$ layers. Arrows indicate valves. a, c: $\times 90, \mathrm{~b}, \mathrm{~d}: \times 180$ 

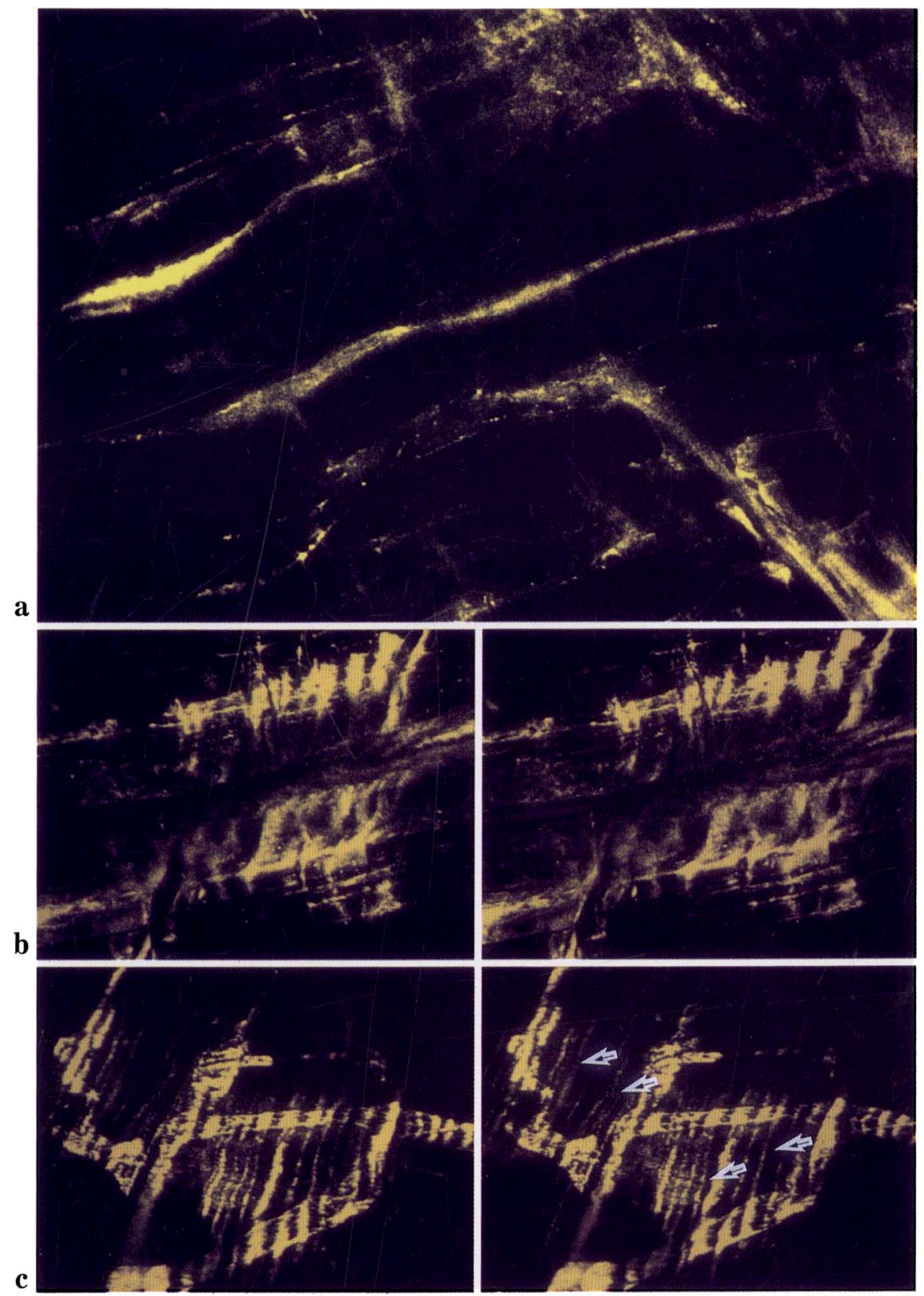

Fig. 9. Confocal laser scanning micrographs of the rat diaphragm after intraperitoneal injection of FITC-dextran. The tracer can be seen not only in the lymphatics but also in the connective tissue spaces (arrows). a: $\times 400$, b, c: stereo-pairs. $\times 100$

stomata. Others of them seemed to correspond to so-called "closed stomata" (SHINOHARA et al., 1989). However, as the number of mesothelial stomata is apparently smaller than that of the foramina in the submesothelial collagen fibers, some of the projections of the lymphatic endothelial cells seem to be only in contact with the mesothelial cells. Such rela- tionships have been repeatedly shown by TEM (BETTENDORF, 1978, 1979; OyA et al., 1993).

The clusters of the foramina in the submesothelial collagen fibrillar sheet deserve further comment. As confirmed by SEM in the monkey (OYA et al., 1993), the present study has also demonstrated the perforated patches of subperitoneal collagen fibers in the rat. 


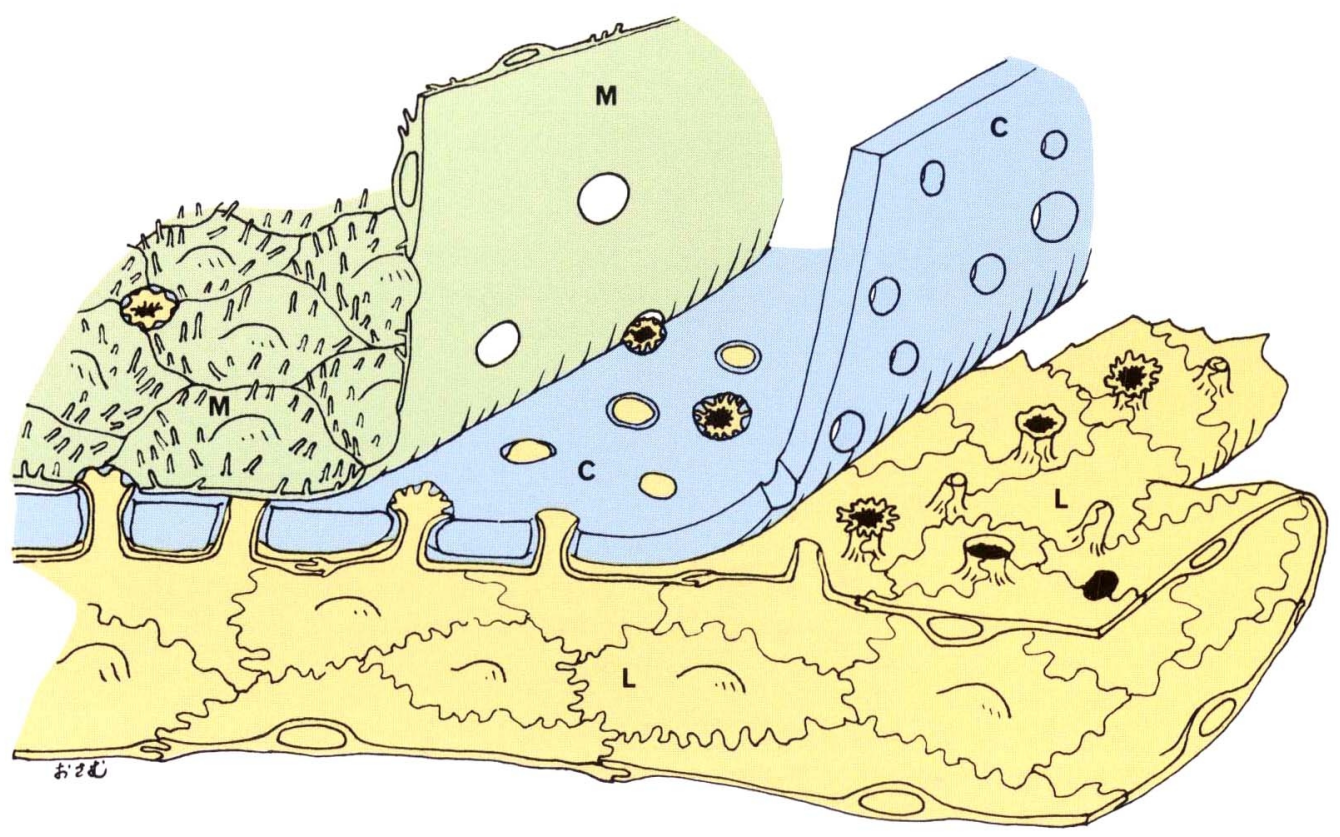

Fig. 10. A schematical drawing of the diaphragm showing three-dimensional relationships between the peritoneal mesothelium $(M)$, the endothelial projections of the lymphatics $(L)$, and the collagen sheet $(C)$ below the mesothelium.

The patches correspond to the "maculae cribriformes" which Tubouchi (1950) initially described by silver impregnation techniques. Obviously, each projection of the lymphatic endothelium fills the foramina made up of collagen fibrils. As also shown by TEM (e.g., BETTENDORF, 1978, 1979; FukUO et al., 1990; Oya et al., 1993), the collagen fibrils around the stomata are lined with lymphatic endothelial cells. As illustrated schematically in Figure 10, the foramina are the places where the funnel-like projections of the lymphatic endothelium pass through and either reach the mesothelial cells to form stomata or touch the mesothelium. In this connection, it does not make any sense to regard the "maculae cribriformes" as specifically representing a "pre-lymphatic (extra-vascular) fluid pathway" (KIHARA, 1956). The connective tissue space, in general, is a kind of "pre-lymphatic fluid pathway".

\section{REFERENCES}

ALlen, L.: On the penetrability of the lymphatics of the diaphragm. Anat. Rec. 124: 639-657 (1956).

BetTENDORF, U.: Lymph flow mechanism of the subperi- toneal diaphragmatic lymphatics. Lymphology 11: 111116 (1978).

BETTENDORF, U.: Electronmicroscopic studies on the peritoneal resorption of intraperitoneally injected latex particles via the diaphragmatic lymphatics. Lymphology 12: 66-70 (1979).

BJerke, H. S., E. S. Adkins and P. Foglia: Surgical correction of hydrothorax from diaphragmatic eventration in children on peritoneal dialysis. Surgery 109: 550554 (1991).

Boeschoten, E. W., R. T. Krediet, C. M. Roos, J. J. KLoек, M. E. I. SchiPPer and L. ARISz: Leakage of dialysate across the diaphragm: an important complication of continuous ambulatory peritoneal dialysis. Netherl. J. Med. 29: 242-246 (1986).

Cotran, S. and J. KaRnOvsKY: Ultrastructural studies on the permeability of the mesothelium of horseradish peroxidase. J. Cell. Biol. 37: 123-137 (1968).

Digenis, G. E., S. Rabinovich, A. Medline, H. Rodella, G. WU and D. G. Oreopoulos: Electron microscopic study of the peritoneal kinetics of iron dextran during peritoneal dialysis in the rabbit. Nephron 37: 108-112 (1984).

Di Paolo, N., G. Sacchi, M. De Mia, E. Gaggiotti, L. Capotondo, P. Rosse, M. Bernini, A. M. Pucci, L. ObBa, P. Sabatelli and C. Alessandrini: Morphology of the peritoneal membrane during continuous ambulatory peritoneal dialysis. Nephron 44: 204-211 (1986). 
EDWARDS, S. R. and A. M. UNGAR: Acute hydrothorax: a new complication of peritoneal dialysis. JAMA 199: 853-855 (1967).

FinN, R. and E. W. JowetT: Acute hydrothorax complicating peritoneal dialysis. Brit. Med. J. 2: 94 (1970).

French, J. E., H. W. Florey and B. Morris: The absorption of particles by the lymphatics of the diaphragm. Quart. J. Exp. Physiol. 45: 88-103 (1960).

Fukuo, Y., H. Shinohara and T. Matsuda: The distribution of lymphatic stomata in the diaphragm of the golden hamster. J. Anat. 169: 13-21 (1990).

KATO, S. and R. MIYAUCHI: Enzyme-histochemical visualization of lymphatic capillaries in the mouse tongue: Light and electron microscopic study. Okajimas Fol. Anat. Jap. 65: 391-404 (1989).

KIHARA, T.: Das extravaskuläre Saftbahnsystem. Okajimas Fol. Anat. Jap. 28: 601-621 (1956).

Kotani, M., M. RaI and S. Nakano: Observations with the electron microscope on the absorption of India-ink from the peritoneal cavity of the rabbit. Okajimas Fol. Anat. Jap. 38: 149-173 (1962).

LEAK, L. V. and F. J. BURKE: Ultrastructural studies on the lymphatic anchoring filaments. J. Cell Biol. 36: 129149 (1968).

LEAK, L. V. and K. RAHIL: Permeability of the diaphragmatic mesothelium; The ultrastructural basis for "stomata". Amer. J. Anat. 151: 557-594 (1978).

LoRENTZ, W. B.: Acute hydrothorax during peritoneal dialysis. J. Pediat. 94: 417-419 (1979).

Masada, S., S. IChikaWa, Y. NaKamura, S. UChino and H. KAT0: Structure and distribution of the lymphatic vessels in the parietal pleura of the monkey as studied by enzyme-histochemistry and by light and electron microscopy. Arch. Histol. Cytol. 55: 525-538 (1992).

Miller, B. G., R. I. Woods, H. G. Bohlen and A. P. Evan: A new morphological procedure for viewing microvessels: A scanning electron microscopic study of the vasculature of small intestine. Anat. Rec. 203: 493503 (1982).

OHTANI, 0.: Three-dimensional organization of the connective tissue fibers of the human pancreas: a scanning electron microscopic study of $\mathrm{NaOH}$ treated tissues. Arch. Histol. Cytol. 50: 557-566 (1987).

- : Structure of lymphatics in rat cecum with special reference to submucosal collecting lymphatics endowed with smooth muscle cells and valves. I. A scanning electron microscopic study. Arch. Histol. Cytol. 55: 429-436 (1992).

Ohtani, 0., T. Ushiki, T. Taguchi and A. KikUta: Collagen fibrillar networks as skeletal frameworks: A demonstration by cell-maceration/scanning electron microscope method. Arch. Histol. Cytol. 51: 249-261 (1988).

OYa, M., T. Shimada, M. NaKamura and Y. UChida: Functional morphology of the lymphatic system in the monkey diaphragm. Arch. Histol. Cytol. 56: 37-47 (1993).

Paramsothy, M., C. T. ChUA and H. W. TAN : Unilateral hydrothorax complicating continuous ambulatory peritoneal dialysis: demonstration by $99 \mathrm{~m}$-technetium-tincolloid scintigraphy. Austras Radiol. 29: 311-314 (1985).
RAFFERTY, A. T.: Regeneration of parietal and visceral peritoneum. An electron microscopical study. J. Anat. 115: 375-392 (1973).

Recklinghausen, F. V.: Zur Fettresorption. Arch. Pathol. Anat. Physiol. 26: 172-208 (1863).

Rudnick, M. R., J. F. Coyle, L. H. BeCK and D. K. MCCuRDY: Acute massive hydrothorax complicating peritoneal dialysis, report of 2 cases and a review of the literature. Clin. Nephrol. 12: 38-44 (1979).

Shinohara, H., Y. Fukuo and T. Matsuda: On the presence and function of closed lymphatic stomata in the diaphragm of the golden hamster. Okajimas Fol. Anat. Jap. 66: 69-80 (1989).

Tsilibary, E. C. and S. C. Wissig: Lymphatic absorption from the peritoneal cavity; Regulation of patency of mesothelial stomata. Microvasc. Res. 25: 22-39 (1983).

- : Light and electron microscopic observation of the lymphatic drainage units of the peritoneal cavity of rodents. Amer. J. Anat. 180: 195-207 (1987).

Tuboutr, M.: Über die siebformige Struktur des subendothelialen Bindegewebes, Macula oder Membrana cribriformis, vorgefunden in der Pleura und im Peritoneum der Wiebeltiere und des Menschen (In Japanese). Acta Anat. Nippon. 25: 6-10 (1950).

UshikI, T. and T. IDE: A modified $\mathrm{KOH}$-collagenase method applied to scanning electron microscopic observations of peripheral nerves. Arch. Histol. Cytol. 51: 223-232 (1988).

Verger, C., A. L. Luger, H. L. MOORE and K. D. NolPH : Acute changes in peritoneal morphology and transport properties with infectious peritonitis and mechanical injury. Kidney Int. 23: 823-831 (1983).

W ACHstein, M. and E. Meisel: Histochemistry of hepatic phosphatases at a physiologic pH. Amer. J. Clin. Pathol. 130: 153-176 (1957).

Werner, J. A., M. Schunke and B. Tillann: Histochemical visualization of lymphatic capillaries in the rat: A comparison of methods demonstrated at the posterior pharyngeal surface. Arch. Histol. Jap. 50: 505514 (1987).

Yamagishi, T.: Fine structure of lymph vessels in the abdominal wall of the diaphragm of dog, and their attitude following absorption of China ink. Nagoya Med. J. 7: 1-6 (1961).

Prof. Osamu OHTANI

Department of Anatomy

Faculty of Medicine

Toyama Medical and Pharmaceutical University 2630 Sugitani, Toyama

930-01 Japan

大谷修

930-01 富山市杉谷 2630

富山医科薬科大学医学部

第一解剖学教室 